T H E G L O B A L D Y N A M I C S

O F R A C I A L A N D E T H N I C

M O B I L I Z A T I O N 


\section{SOCIAL INEQUALITY}

\section{EDITORS}

David B. Grusky, STANFORD UNIVERSITY

Paula England, STANFORD UNIVERS ITY

\section{OTHER BOOKS IN THE SERIES}

Poverty and Inequality

Edited by David B. Grusky and Ravi Kanbur 2006

Mobility and Inequality: Frontiers of Research in Sociology and Economics Edited by Stephen L. Morgan, David B. Grusky, and Gary S. Fields 2006

On the Edge of Commitment: Educational Attainment and Race in the United States

By Stephen L. Morgan

2005

Occupational Ghettos: The Worldwide Segregation of Women and Men By Maria Charles and David B. Grusky 2004

Home Ownership and Social Inequality in Comparative Perspective Edited by Karin Kurz and Hans-Peter Blossfeld 2004

Reconfigurations of Class and Gender Edited by Janeen Baxter and Mark Western 2001

Women's Working Lives in East Asia Edited by Mary C. Brinton 2001

The Classless Society By Paul W. Kingston 2000 
THE GLO B A L D Y NA M I C O F R A C I A L A N D E T H N I C M O B I L I Z A T I O N

Susan Olzak

STANFORD UNIVERSITY PRESS

ST A N F OR D, CA L I F ORNIA 
Stanford University Press

Stanford, California

(C) 2006 by the Board of Trustees of the Leland Stanford Junior University. All rights reserved.

No part of this book may be reproduced or transmitted in any form or by any means, electronic or mechanical, including photocopying and recording, or in any information storage or retrieval system without the prior written permission of Stanford University Press.

Library of Congress Cataloging-in-Publication Data

Olzak, Susan.

The global dynamics of racial and ethnic mobilization / Susan Olzak.

p. $\mathrm{cm}$.

Includes bibliographical references and index.

ISBN 0-8047-3998-6 (cloth : alk. paper)

ISBN 0-8047-7862-0 (pbk. : alk. paper)

1. Ethnicity-Political aspects. 2. Ethnic conflict.

3. Political violence. 4. Culture and globalization. 5. Social movements. 6. Social integration. I. Title.

GN495.6.O49 2006

$305.8-\mathrm{dc} 22$

2005032416

Original Printing 2006

Last figure below indicates year of this printing:

$\begin{array}{lllll}15 & 16 & 13 & 12 & 11\end{array}$ 
THIS BOOK IS DEDICATED TO

Suzanne Shanahan

FOR HER PERSEVERANCE, INTELLIGENCE, AND COURAGE. 

C O N T E N TS

List of Figures and Tables ix

List of Abbreviations $\quad x i$

Preface and Acknowledgments xiii

CHAPTER ONE World Integration and Centrifugal Forces 1

CHAPTER Two Definitions and Dynamics of Racial/Ethnic

Mobilization 33

CHAPter three Escalation and De-escalation: Trends in the Data 78

Chapter four Globalization and Nonviolent Ethnic Protest, 1965-1989 93

CHAPTER FIVE Global Integration and Ethnic Violence, 1965-1989 116

Chapter six Group Dynamics of Ethnic Protest and Conflict, 1980-1994 131

Chapter seven Globalization in a New Era: Ethnic Violence since 1989 152

CHAPTER EIght Democracy, Ethnic Violence, and International War 169

CHAPTER NINE Models Incorporating Endogeneity 196

CHAPTER TEN Conclusions and Future Considerations 212

Appendix A: Countries in the Analysis in Chapters 4-6 235

Appendix B: Countries in the Analysis in Chapters 7-9 237

References 240

Name Index 259

Subject Index 264 

Figures

1.1 Heuristic Model of the Interplay among World-, Country-, and Group-level Forces and Ethnic Mobilization 27

3.1 Percentage of Groups with Major Ethnic Activity, MAR Data 82

3.2 Percentage of Countries with Major Ethnic Activity, MAR Data 83

3.3 Annual Number of Ethnic Events, PANDA Data 88

3.4 Violent and Nonviolent Ethnic Events, PANDA Data 89

3.5 State Repression and Ethnic Violence, PANDA Data 90

3.6 State Repression and Nonviolent Ethnic Events, PANDA Data 91

Tables

1.1 Location of Authority and Basis of Social Interests in Polities 19

2.1 Forms of Ethnic Mobilization 43

3.1 Categories of Nonviolent Ethnic Protest and Ethnic Rebellion, Minorities at Risk Data Set 80

4.1 Number and Percentage of Countries Experiencing Different Magnitudes of Nonviolent Ethnic Protest, 1965-1989 102

4.2 Relationship of Peripheral Status in the World System and Magnitude of Nonviolent Ethnic Protest, 1965-1989 109

4.3 Comparing Cross-Sectional and Panel Estimates of Effects on the Magnitude of Nonviolent Ethnic Protest, 1965-1989 110

5.1 Number and Percentage of Countries Experiencing Different Magnitudes of Violent Ethnic Rebellion, 1965-1989 118 
5.2 Relationship of Peripheral Status in the World System and Magnitude of Violent Ethnic Rebellion, 1965-1989 122

5.3 Cross-Sectional and Panel Estimates of Effects on Magnitude of Violent Ethnic Rebellion, 1965-1989 124

6.1 Number and Percentage of Groups Experiencing Different Magnitudes of Nonviolent Ethnic Protest, 1970-1994 137

6.2 Number and Percentage of Groups Experiencing Different Magnitudes of Violent Ethnic Rebellion, 1970-1994 138

6.3 Effects of Ethnic and Racial Group Characteristics on Levels of Ethnic Protest and Rebellion, 1980-1994 144

7.1 Number and Percentage of Groups Experiencing Different Magnitudes of Violent Ethnic Rebellion, 1990-1998 157

7.2 Effects of World System Status on Magnitude of Violent Ethnic Rebellion, 1995-1998 159

7.3 Effects of World System Status on Annual Counts of Ethnic Violence, 1989-1995 163

8.1 Effects of Political Structure on Annual Counts of Ethnic Violence, 1989-1995 184

8.2 Democratic Regimes, Ethnic Violence, and War, 1989-1995, Ordinal Logit Models 188

8.3 Civil Rights, Ethnic Violence, and War, 1989-1995, Ordinal Logit Models 192

9.1 Ethnic Violence and Violent State Response, 1984-1995, GLS Panel Model Estimates 199

9.2 Effects of State Violence on Ethnic Violence, 1984-1995, TwoStage Least Squares Panel Estimates 201

9.3 Effects of State Violence on Nonviolent Ethnic Protest, 19841995, Two-Stage Least Squares Panel Estimates 207 
A B B R E V I A T I O N S

COW Correlates of War (data set)

ELF Ethnic Linguistic Fractionalization (index)

GDP Gross Domestic Product

IGOs International Governmental Organizations

INGOs International Non-governmental Organizations

KEDS Kansas Event Data System

MAR Minorities at Risk (data set)

PANDA Protocol for the Assessment of Nonviolent Direct Action

POS Political Opportunity Structure (theory) 

My purpose in undertaking this research is to offer an examination of theoretical arguments that focus on the global scope of racial and ethnic events as they have unfolded in the contemporary period. As most scholars know, the majority of research on ethnic movements has generated numerous case studies with rich historical detail, but it has not generated much in the ways of generalizable and testable propositions. Moreover, scholars have focused mainly on local factors of inequality, ethnic entrepreneurs, or failed state structures to explain outbreaks of violence or protest. Because relatively few theoretical arguments at the global level have been offered, country-level analysis has dominated the study of ethnic conflicts, protest, and violence. In this book I argue that there are specific advantages to moving away from a sole concern with local mechanisms that spark ethnic conflict and protest. By emphasizing global processes that link the fates of movements and the states they challenge, I find that country- and group-level factors are just part of the story.

My argument holds that to the degree that states participate in world organizations, ethnic mobilization will be more likely. Beyond this ethnic activation process, national economic and political factors further channel the form that mobilization will take. Thus, I seek to contribute to the existing literature, which has largely ignored the global context of ethnic movements. I explore two different data sets on ethnic conflict and protest to achieve this end. One source of information is the Minorities at Risk data set, painstakingly collected and updated by Ted Gurr and his associates. These data provide categorical information on ethnic mobilization that addresses questions about the magnitude and scope of ethnic protest and conflict. Because the data were collected at the ethnic-group level, they allow researchers the flexibility of moving from ethnic-group to national levels of analysis. My second data set on ethnic conflict and protest was provided to me by Doug Bond 
and his associates, as part of their larger effort of data collection using the PANDA parsing method for coding events directly from daily newspaper accounts published by Reuters news service. The PANDA data set yields information on the timing and location of ethnic events anywhere in the world recorded by this news organization. Together, these large and comprehensive data sets allowed me to ask several key research questions:

1. What is the trajectory of ethnic and racial mobilization in recent decades? Many scholarly treatments of ethnic violence, conflict, and activation of ethnic boundaries begin with the assumption that ethnic identity has provoked and sustained major group conflict since World War II, and many more warn that ethnicity threatens the foundation of the nation-state, and the division of geography and administrative units into state organizations. Because this assumption has been rarely examined empirically, this book takes on this task as its first goal.

2. What is the relationship between ethnic conflict and protest? Are the causal factors the same or different, and if different, how? This question focuses on theories and arguments relating nationalism, social movements, and peaceful forms of political claims-making to more contentious and violent forms of activity based on ethnic identity. At its most basic level, this book formulates an argument that links ethnic conflict and process to global economic, political, and social processes that have become increasingly important at the local level, activating (or re-activating) ethnic boundaries that now make claims on a world platform.

3. Do links to the world economic and diplomatic network moderate ethnic tensions or exacerbate them and lead to ethnic and nationalist social movements? A vast array of literature suggests that inequality and political opportunities vary across countries, shaping and channeling social-movement activity of all kinds. Yet few studies have considered whether global links among organizations expressly created for the purpose of affecting policy outcomes at the world level might interact with these national-level factors. This book offers an argument that global processes and links among international actors provide the motivation and means for ethnic actors within countries to motivate ethnic populations within and across national boundaries.

\section{Guide to the Chapters}

As is often the case, various chapters of this book will be more and less useful to readers with differing interests, tastes, and disciplinary backgrounds. In this section, I provide a few guidelines to different sections of the book. Chapters 1-3 are discursive and less technical, while Chapters 4-9 present quantitative estimates of the effects of group-, national-, and global-level factors associated with ethnic mobilization. 
For readers seeking an overview, my main arguments are summarized in the introductory Chapter 1 and the concluding Chapter 10. Chapter 2 reviews a number of conceptual definitions and distinguishes my definitions from alternative formulations. For those readers who are familiar with the literature on ethnicity, ethnic identity, social movements, and nationalism, this chapter will be less relevant. Chapter 3 provides a general temporal overview of empirical data, and begins to sketch several alternative interpretations of these trends. Chapters 4, 5, and 6 examine sources of the magnitude and scope of ethnic protest and conflict. They present quantitative results using the Minorities at Risk data set on ethnic nonviolent protest and conflict, and the analyses distinguish between pre- and post-Cold War periods. Chapter 7 examines the temporal and spatial distribution of reports on ethnic activity since the end of the Cold War. In this chapter, I compare the effects of cultural, linguistic, and competition factors using data from the Minorities at Risk and the PANDA data sets. Chapter 8 uses data on ethnic violence, internal war, and international war to explore the influence of a number of political structures and opportunities on these outcomes. This chapter compares the effects of democracy, civil rights, and geographical contagion on ethnic violence with their effects on other types of warfare. Chapter 9 explores issues of two-way causation between state repression and ethnic conflict. It applies a number of methodological procedures that raise (but do not always solve) a number of questions about the endogeneity of the process, specifically trying to sort out whether fragile or undemocratic states create political opportunities for ethnic violence, or whether ethnic violence creates situations that make it difficult to sustain democracy.

\section{Acknowledgments}

This research monograph was partially funded by a fellowship-in-residence (2000-2001) provided by The Netherlands Institute for Advanced Study (NIAS). The author thanks Ted Gurr and Monty Marshall for providing the Minorities at Risk data set on the intensity of protest, violence, and rebellion. Ann Hironaka (2000, personal communication) shared her annual timeseries of international governmental and non-governmental organizations. Doug Bond provided cross-national data on ethnic protest, conflict, and rebellion, from the Protocol for the Assessment of Nonviolent Direct Action (PANDA data set), in collaboration with the Program on Nonviolent Sanctions and Cultural Survival, Weatherhead Center for International Affairs, Harvard University. Excellent research assistance in assembling the PANDA 
data was provided by Sean Everton and Evan Schofer. Stanford colleagues James Fearon and David Laitin provided stimulating criticism, information and data, and support for this project. Many of the original ideas about the diffusion of human rights ideology come from John Meyer's brilliant work on the world polity, and I have drawn from this as well as from the work of many of his students, including John Boli, Chris Chase-Dunn, Ron Jepperson, Ann Hironaka, Francisco Ramirez, Evan Schofer, Suzanne Shanahan, Yasemin Soysal and George Thomas. I have had a large group of colleagues at Stanford and in the Netherlands who commented on my interpretations and pushed me to clarify my arguments. In particular, Al Bergesen, Daniel Chirot, Meindert Fennema, Michael Hannan, Jonathan Haynes, Michael Hechter, Ron Jepperson, Laura López-Sanders, John Meyer, Shushanik Makaryan, Emily Ryo, Suzanne Shanahan, Evan Schofer, and Sidney Tarrow provided excellent suggestions, criticisms, and encouragement, and I thank them all. 
T H E G L O B A L D Y N A M I C S

$\begin{array}{llllllllllllllllll}O & F & R & A & C & I & A & L & A & N & D & E & T & H & N & \text { I } & C\end{array}$ M O B I L I Z A T I O 
